\title{
The Power of Magnification in Dentistry
}

\author{
Shady Negm* \\ Faculty of Dentistry, Pharos University in Alexandria, Egypt
}

Submission: February 10, 2017; Published: March 24, 2017

*Corresponding author:Shady Negm, BDS, DDI, F-ICOI, F-AOIA, Faculty of Dentistry, Pharos University in Alexandria, Egypt,

Email: shady.negm@pua.edu.eg

\section{Abstract}

Traditional endodontic has been based on feel not sight. Together with radiographs and electronic apex locators this blind approach has produced surprising success. There is, however, a significant failure rate, especially in long-term. Magnification helps the user not only to see more, but to see well. High levels of magnification increase the aggregate amount of visual information available to endodontists for diagnosing and treatment. Also for improving ergonomics clinically, most dental practitioners will not be able to see an open margin smaller than $0.2 \mathrm{~mm}$. The film thickness of most crown and bridge cements is $25 \mu \mathrm{m}(0.025 \mathrm{~mm})$, well beyond the resolving power of the naked eye. That's why magnifiers appeared.

Dental loupes of different brands, types, and specifications coupled with a lack of information available to determine the right loupes for you. It's no wonder that choosing a pair can be a daunting prospect for both students and dentists alike.

Dentistry involves operating in small dark areas, performing procedures that require extreme precision. Dental loupes allow you to see a more detailed working site, at an increased magnification. This improved visibility allows you to identify critical details such as root canals, fractures or open crown margins thus allowing you to diagnose and treat to a higher standard. Attach a light to the loupes, and you'll no longer suffer from shadowing in the mouth (Figure 1).

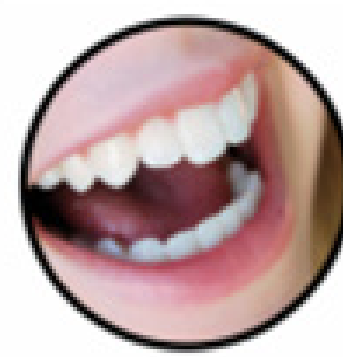

$0 x$

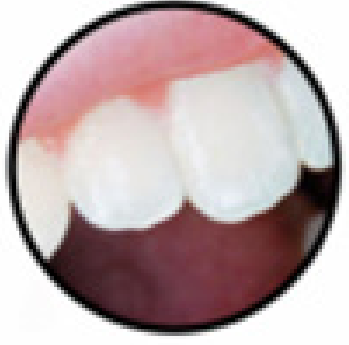

$2.5 x$

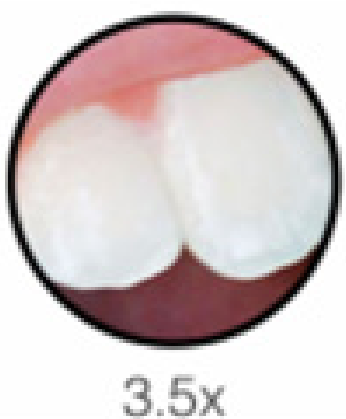

$3.5 x$

Figure 1

\section{Type your Superior Ergonomics}

Dentists experience a greater amount of neck and back pain than any other profession - with around 70\% reporting musculoskeletal pain. This can develop even as a dental student. Poor vision and insufficient lighting when performing dental treatment often results in poor operator posture. Loupes force you to maintain a healthier posture, thus reducing this problem.

There are two types of loupes available, and are classified based on the positioning of the optics:

\section{Flip up loupes}

They have the optics attached to a movable arm, and can be manually adjusted to suit anyone with advantages of much cheaper,
Easily flipped up when not required (good for communicating with the patient), better resale value and Easier to add prescription. Also, disadvantages are heavier and smaller field of view.

\section{Through the lens (TTL) loupes}

They have the optics built into the glasses, with the specifications (such as inter-pupillary distance) customised to your eyes with advantages of lighter weight, Wider field of view (as the optics are closer to the eyes) and Optics will always be in the right position. The disadvantages are much more expensive, Cannot be moved from the view, so more difficult to communicate with the patient and Poor resale value (as only suited to the clinician they are set to). 


\section{Some Considerations Should be in Magnifiers}

\section{Good power}

A range of magnifications are available, with the most common being $2.5 \mathrm{x}$ and 3.5x.Increased magnification provides a more detailed working site. However, there are some downsides: Smaller field of view, Darker field of view (decreased light enters the lens) and Steeper learning curve for new users. You may come across the terms Galilean (lower magnification) and Prismatic (high magnification, more expensive) loupes. Ideal magnification: For general dental and hygiene work, $2.5 \mathrm{x}$ magnification is universally recommended. For more detailed work (egendodontics), a higher magnification such as $3.5 \mathrm{x}$ and beyond is advised.

\section{Resolution}

Resolution is the ability of loupes to distinguish between two closely spaced objects. In other words, it refers to the clarity of the image, which is in turn determined by the quality of the optics. For example, think about the quality of a projected image vs the quality of your mobile phone screen. Ideal resolution: unfortunately, the only way you can determine resolution is by trying the loupes on yourself.

\section{Depth of field}

The depth of field refers to the range of distances in which the object remains in focus. It determines how much you can lean into or away from the object (eg, if your depth of field is $20 \mathrm{~cm}$, you can move $10 \mathrm{~cm}$ closer to and $10 \mathrm{~cm}$ away from the object and it will remain in focus). It is important to have a generous depth of field to reduce fatigue. Ideal depth of field: around $10 \mathrm{~cm}$ should be sufficient.

\section{Field of view}

This term simply refers to the area visible through the loupes. Is the view zoomed in on one tooth, or can you see an entire quadrant? A larger field of view is preferred as it allows more to be seen, easier introduction of instruments into the operating area, and reduces eye strain. Ideal field of view: for a pair of $3.5 \mathrm{x}$ mag, a field view of around $7 \mathrm{~cm}$ (although remember this will decrease with increasing magnification). Choose a pair that allows you to see everything you need to see for your day to day procedures.

\section{Your next submission with Juniper Publishers will reach you the below assets}

- Quality Editorial service

- Swift Peer Review

- Reprints availability

- E-prints Service

- Manuscript Podcast for convenient understanding

- Global attainment for your research

- Manuscript accessibility in different formats ( Pdf, E-pub, Full Text, Audio)

- Unceasing customer service

Track the below URL for one-step submission https://juniperpublishers.com/online-submission.php 